Article

\title{
Post-Processing of VIS, NIR, and SWIR Multispectral Images of Paintings. New Discovery on the The Drunkenness of Noah, Painted by Andrea Sacchi, Stored at Palazzo Chigi (Ariccia, Rome)
}

\author{
Lucilla Pronti ${ }^{1, *,+} \oplus$, Martina Romani ${ }^{1, *,+}$, Gianluca Verona-Rinati ${ }^{2, *, \dagger}$, Ombretta Tarquini ${ }^{3, *,+}$, \\ Francesco Colao ${ }^{4,+}$, Marcello Colapietro ${ }^{3,+}$, Augusto Pifferi ${ }^{3,+}$ (i) , Mariangela Cestelli-Guidi ${ }^{1,+}+(\mathbb{D})$ \\ and Marco Marinelli ${ }^{2, \dagger}$ \\ 1 INFN-Laboratori Nazionali di Frascati, Via E. Fermi 40, 00044 Frascati, Italy \\ 2 INFN-Dipartimento di Ingegneria Industriale, Università degli Studi di Roma Tor Vergata, \\ Department of Industrial Engineering, Via del Politecnico 1, 00133 Roma, Italy \\ 3 C.N.R. Istituto di Cristallografia - Area della Ricerca Roma 1, Via Salaria Km 29300, 00015 \\ Monterotondo (RM), Italy \\ 4 ENEA, Italian National Agency for New Technologies, Energy and Sustainable Economic Development, \\ Via E. Fermi 45, 00044 Frascati (RM), Italy \\ * Correspondence: lucilla.pronti@lnf.infn.it (L.P.); martina.romani@lnf.infn.it (M.R.); \\ gianluca.verona.rinati@uniroma2.it (G.V.-R.); ombretta.tarquini@mlib.ic.cnr.it (O.T.) \\ + These authors contributed equally to this work.
}

Received: 30 June 2019; Accepted: 30 July 2019; Published: 2 August 2019

\begin{abstract}
IR Reflectography applied to the identification of hidden details of paintings is extremely useful for authentication purposes and for revealing technical hidden features. Recently, multispectral imaging has replaced traditional imaging techniques thanks to the possibility to select specific spectral ranges bringing out interesting details of the paintings. VIS-NIR-SWIR images of one of the The Drunkenness of Noah versions painted by Andrea Sacchi, acquired with a modified reflex and InGaAs cameras, are presented in this research. Starting from multispectral images we performed post-processing analysis, using visible and infrared false-color images and principal component analysis (PCA) in order to highlight pentimenti and underdrawings. Radiography was performed in some areas to better investigate the inner pictorial layers. This study represents the first published scientific investigation of The Drunkenness of Noah's artistic production, painted by Andrea Sacchi.
\end{abstract}

Keywords: paintings; Andrea Sacchi; multispectral imaging; radiography; reflectography; false-color image; PCA

\section{Introduction}

Infrared reflectography has been widely employed as preliminary investigation of paintings to evaluate the state of conservation, reveal underdrawings and provide similar and/or complementary information to the radiography [1,2]. The possibility to visualize the underlying drawing is related to the fact that many pigments result to be transparent to IR radiation in the infrared region of the electromagnetic spectrum. For this reason, a high contrast between the materials used for the drawing, like carbon black or black bone, and the preparation layer, consisting of chalk or white lead, is obtained. In some cases, infrared reflectography does not show underdrawings, but pictorial spreads that belong to a previous idea of the painting composition. These pictorial layers and changings in the drawing, which is concealed under the final pictorial layer, are hidden to an external observer and could be 
defined as pentimenti. Their visualization permits to acquire an important knowledge of the evolution of the artist's compositional project, revealing the mental process behind the final appearance of the painting [3]. Usually, copies do not show significant pentimenti due to the fact that the painter replies a model. As a matter of fact, reflectograms could highlight the grids used to transpose the original painting to a different scale [4]. This means that the studies of the underdrawings or pentimenti and the sketches, concerning a series of paintings and representing the same subject, are extremely important to determinate their temporal execution. Furthermore, the discovery of pentimenti can help to establish the originality of an artwork since a forgery often represents a faithful copy of the original or, at least, is realized without relevant changes.

The infrared reflectography is performed by illuminating the painting with infrared radiation and collecting the infrared radiation backscattered from the painting with a dedicate detector. The less expensive acquisition system consists of two light sources, which uniformly illuminate the painting surface and a digital camera equipped with different filters to take images in different spectral range. The IR reflectography can be performed by using several types of cameras with different image sensors. Cameras for NIR (Near Infrared Reflectography) imaging use silicon-based sensors, which can detect photons up to $1100 \mathrm{~nm}$ (even if the signal to noise ratio is very low at these wavelengths), while the other ones are properly projected for applications in the IR ranges. The early systems used $\mathrm{PbO}-\mathrm{PbS}$ vidicon cameras with sensitivities up to $2200 \mathrm{~nm}$; more suitable systems use InGaAs or PtSi detectors with a broader sensitivity.

Usually, IR reflectography is carried out using a long-pass filter (in order to remove the UV-VIS portions of the spectrum) and capturing the IR image in a single large band. The acquired information is integrated over the broad spectral range instead of being obtained in a spectral narrow band.

For this reason, over the last decade, multispectral imaging has gained importance in the cultural heritage field, since it allows to select a specific IR portion in which the painted layers present low absorbance and granting a better visualization of the background layers $[5,6]$.

Multispectral imaging was developed 40 years ago and its use was mainly restricted to astrophysics, remote sensing, and terrestrial military applications until the 1990s. This technology has undergone a rapid development during the last 20 years and has been applied in many research fields, such as the remote sensing of Earth's atmosphere [7], the detection of contaminants on food [8], the analysis of plants and fruits [9], and the diagnostic of cancer tissue [10].

Multispectral imaging permits to acquire a set of two-dimensional images at different wavelengths within a given spectral range. In this way, spatial and spectral information are simultaneously recorded: The light intensity is registered as a function of both location (pixel of the image) and wavelength. For the sake of the good order, another technique which is based on the same principles should be mentioned: 'Hyperspectral imaging. This technique differs from multispectral imaging because of the number of spectral images produced: Less than 12 in the multispectral imaging and much more in the hyperspectral system [11].

The post-processing represents an important step for a proper interpretation of multispectral images. Indeed, the development of digital acquisition procedures has permitted post-processing of raw images by the application of typical digital image processing algorithms, such as contrast stretching and luminance transformation filters (gamma, logarithmic, etc.). However, thanks to the modern image processing it is possible to achieve a more accurate radiometric calibration so that all images are corrected by the spectral sensitivity of the camera sensor and the spectral transmittance of optical lens and filters. Starting from calibrate images, it is possible to perform several post-processing procedures as false-color images and chemometric image analysis (PCA, PLS, K-means, etc.), in order to emphasize spectral features which are not evident in the raw data set [12-15].

The most traditional post-processing technique is the so called false-color image, which is a rendering method used to display colored images recorded in the visible and IR regions. Traditional false-color photography has been comprehensively used as a guide for identification of pigments. The experimental procedure requires the combination of RGB color images and IR reflectogram, in which 
the image taken in the green range of the electromagnetic spectrum (centered at about $500 \mathrm{~nm}$ ) replaces the blue image (B), the image taken in the red range (centered at about $600 \mathrm{~nm}$ ) replaces the green image $(G)$, and the IR reflectogram substitutes the red image (R) [16-19]. This approach is very useful to recognize pigments which have large differences in the IR absorbance, although they appear similar to the eye (i.e., lapis lazuli shows a red false-color with respect to the much less expensive azurite that looks blue [20]). However, since any combination of three different images (not mandatorily corresponding to the ones just mentioned) could be defined as "False-color image", new perspectives are open to image processing, not necessarily involving IR range but aiming to underline different spectral features even in the visible range [21].

The second step is applying suitable chemometric approaches which have proven to be powerful tools to reduce data dimensionality, detecting hidden patterns also removing noise and redundant correlated data [22,23]. One of the most used chemometric methods in the analysis of paintings is the principal component analysis (PCA) that is a multivariate linear method which allows to represent data in a set of new loading, called principal components [24]. PCA is applied to the diagnostic imaging of paintings mainly for the recognition of pictorial materials [25-27] or to identify pictorial drafting and restoration works [28,29].

The new frontier for the analysis of multimodal images is the multisensor data fusion, that is a technology to enable combining information from several sources in order to form a unified data set to be processed [30]. Paintings are good objects to apply data fusion technique due to the fact that their surface heterogeneities and complex stratigraphies required different analytical methods, experimental set ups and devices to be analyzed [31-33].

In this research, false-color images and PCA of data fusion of visible and IR images of the painting The Drunkenness of Noah painted by Andrea Sacchi is presented.

Some areas were compared with the radiography images which represent the complementary imaging technique par excellence.

The importance of applying VIS-NIR-SWIR reflectrography, radiography, and post-processed imaging on this painting is related to the fact that it could be the first version of the four oil paintings representing Drunkenness of Noah painted by Andrea Sacchi. This study represents the starting point for the scientific investigation of these paintings through the observations of pentimenti and the stylistic, artistic, and documental support of the conservators and humanistic researchers, with the aim to define which painting of them represents the first version.

\section{Materials and Methods}

\subsection{The Painting}

The Drunkenness of Noah represents a biblical scene (Genesi 9, 20-27) in which Noah is sleeping naked after getting drunk on his wine. His third son, Ham, saw his father unclothed and showed it to his two brothers (Shem and Japhet). They put a wrap on their backs and reclined it to cover his father with their faces turned away.

The painting analyzed in this research is an oil on canvas $(150.5$ by $205.8 \mathrm{~cm}$ ) and one of the four observable versions. This is stored in Palazzo Ghigi in Ariccia (Rome) and it is shown in Figure 1. It belongs to a British private collection and it was purchased from Sotherby's (New York) in 2009. The other versions painted by the same artist are stored in: (1) Provincial Museum of Catanzaro (Italy), (2) Staatliche Museum of Berlin (Germany), (3) Kunsthistorisches Museum of Vienna (Austria) [34]. 


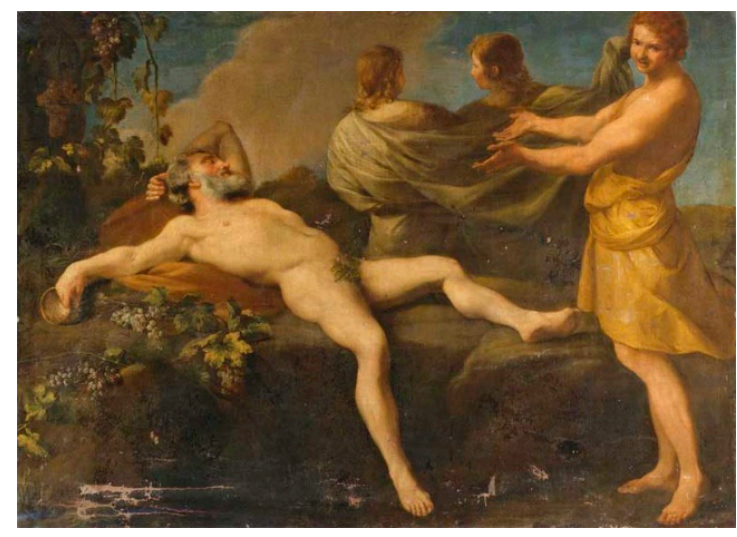

(a)

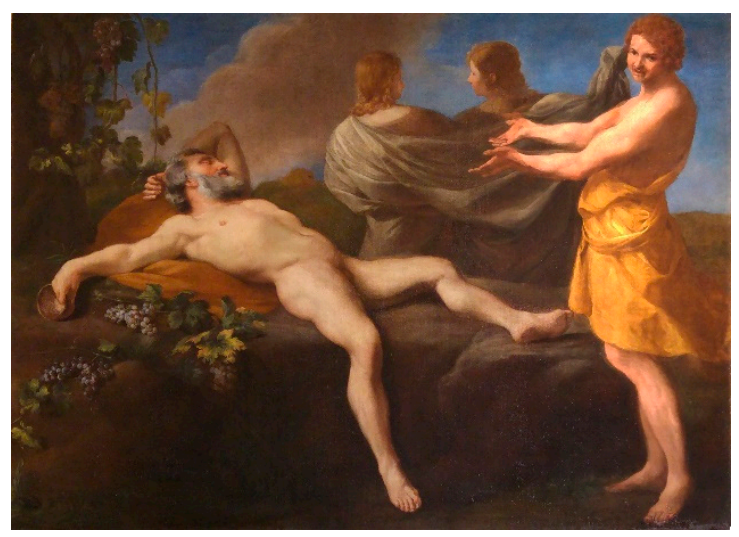

(b)

Figure 1. The painting The Drunkenness of Noah placed at Palazzo Chigi (Ariccia) before (a) and after (b) restorations.

The painting placed at Palazzo Chigi in Ariccia was restored in 2010 by removing ancient varnishes and repainting, which were realized to cover the Noah's intimate parts, as showed in Figure 1a.

\subsection{VIS-NIR-SWIR Multispectral Imaging}

The VIS and NIR multispectral imaging were performed with a NIR converted camera (Nikon D7100) equipped with a Si sensor, in the spectral range of 370-1100 nm, with a resolution of 24.1 MegaPixel. The camera is equipped with four Edmund Optics filters: One IR cut and three long pass filters above $780 \mathrm{~nm}, 830 \mathrm{~nm}$, and $1000 \mathrm{~nm}$. SWIR camera (XENICS “Xeva-1.7-640") has an InGaAs sensor with the spectral range at $900-1700 \mathrm{~nm}$, a resolution of $640 \times 512$, a pixel pitch of $20 \mu \mathrm{m}$ and an array cooling (TE1-cooled down to $263 \mathrm{~K}$ ).

All the multispectral images were properly radiometrically calibrated: For each acquisition, an image of the painting with a reflectance standard (spectralon white diffuse reflectance standard, Edmund Optics) was recorded. Then, each image was normalized to the spectral energy reflected in the acquisition band by the reflectance standard, in order to have images corrected by both the spectral sensitivity of the cameras and the spectral transmittance of the optical lens and the filters. To illuminate, we used two halogen bulbs (Uniflood $300 \mathrm{~W}, 3350 \mathrm{~K}$, Cosmolight) placed at 45 degrees with respect to the normal of the painted surface.

The images were registered by using ImageJ (an open source image processing software) and post-processed by using MATLAB 2017a integrated by Hypertools (Free Graphical User Interface for Hyperspectral Image Analysis). The VIS-NIR-SWIR images were also stacked in a multispectral cube and then combined in a false-color image (called also raw data). We performed PCA on the multispectral image cube, which is a chemometric processing method that carries out a linear transformation which decorrelates multivariate data by translating and/or rotating the axes of the original space. In this way, the data can be represented without any correlation in a new component space. Each component explains a certain percentage of the variance: The first component (PC1) explains the maximum variance, the second component (PC2) another consistent part. and so on, until reaching the $100 \%$ of the explained variance.

\subsection{Radiography}

The Radiography was performed with a tungsten X-ray source and an Image Plate detector (IP) with a reading system (Kodak CR7400) that allows obtaining digital image with the dimension of $18 \times 24 \mathrm{~cm}, 16$ bit gray scale, and a resolution of $600 \mathrm{dpi}$. The operating conditions were $38 \mathrm{kV}$ and 1 MAS. 


\section{Results and Discussion}

Several pentimenti were detected by capturing NIR and SWIR multispectral images, as shown in Figure 2. By acquiring images at different spectral ranges, the readability of underdrawings is increased because of the fact that each pictorial layer is differently transparent in the IR range. Since it is impossible to know a priori of the whole chemical composition of the painting, multispectral imaging approach is always recommended. For each IR multispectral image, we can already recognize differences with the visible image by a point-to-point comparison. However, this approach results as a slow method and it depends on the capacity to find changes in gray scale images. Thus, in order to better emphasize differences between the visible image and infrared ones, we generated a false RGB by replacing the red channel $(R)$ with the image obtained from the InGaAs image, the green channel $(G)$ with the image acquired by the Si sensor with the longpass filter at $1000 \mathrm{~nm}$, and the blue channel (B) acquired by the Si sensor with the IR cut filter image.

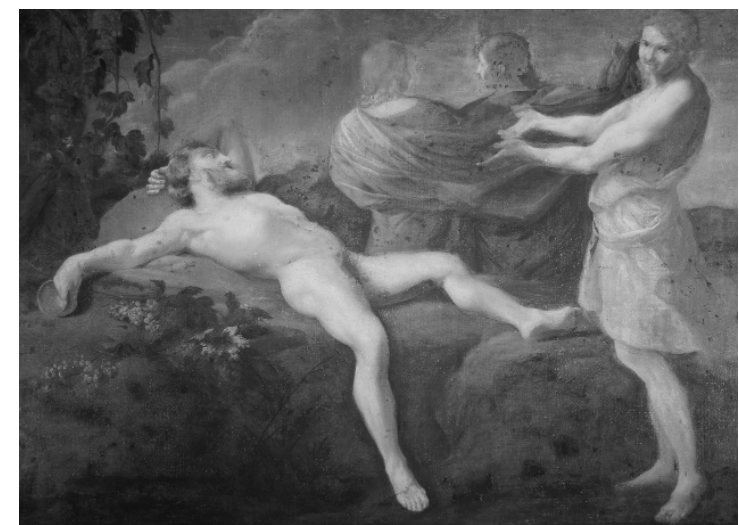

(a)

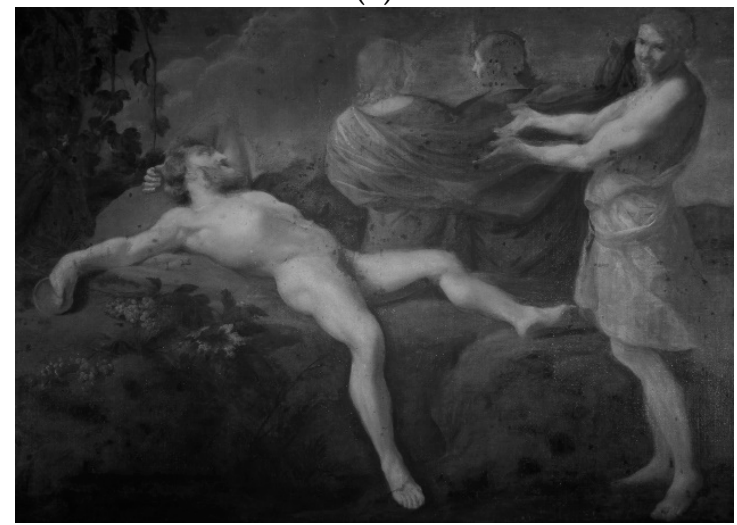

(c)

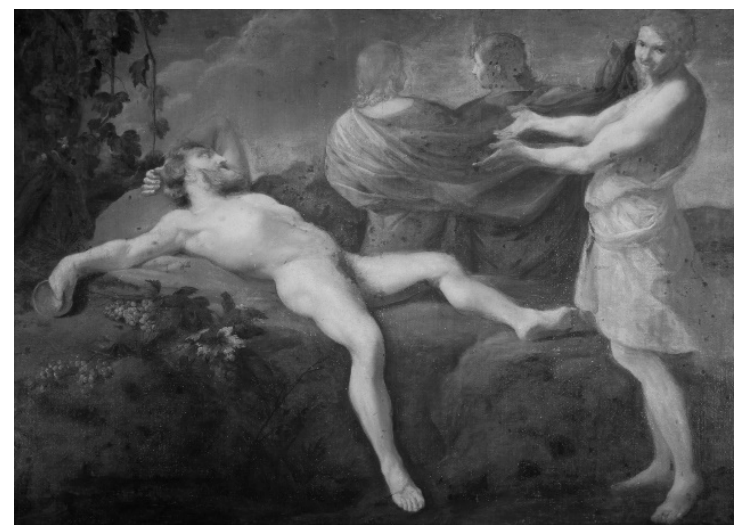

(b)

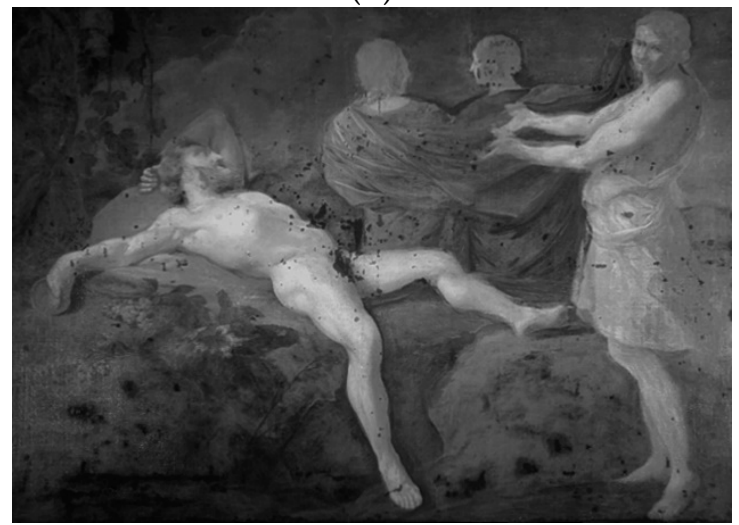

(d)

Figure 2. Gray scale rendering of the reflectance images of the painting, taken with longpass filter at $780 \mathrm{~nm}(\mathbf{a}), 830 \mathrm{~nm}(\mathbf{b}), 1000 \mathrm{~nm}(\mathbf{c})$, and with the InGaAs camera (d).

The resulting image (Figure 3) shows some dark blue areas corresponding to the restoration integrations, see Figure 1b, appearing as lines in the bottom part of the painting. Other dark blue areas regard portions of the painting that were subjected to the removal of repainting. This means that the restauration materials used have low reflectivity under IR radiation. 


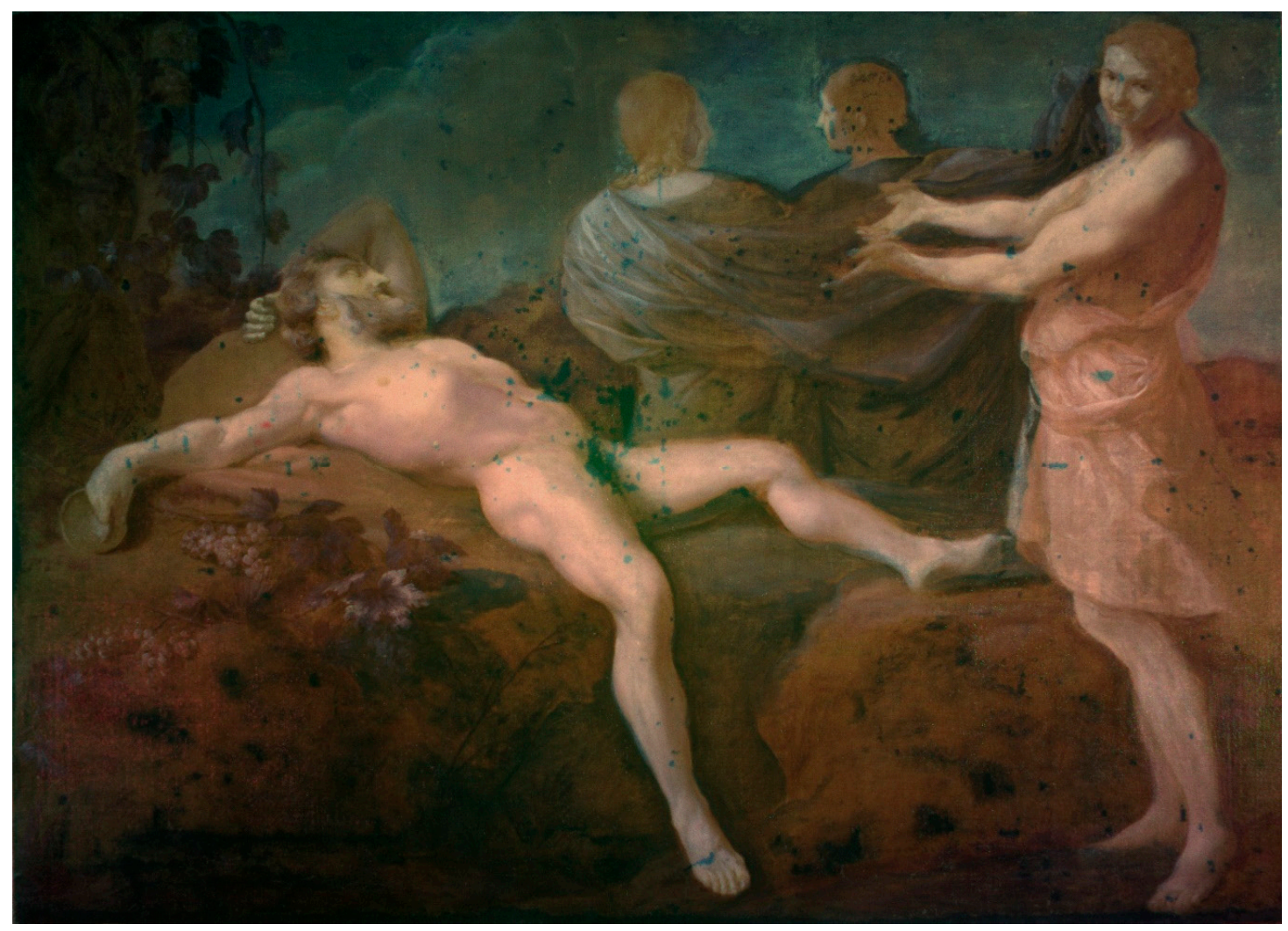

Figure 3. False-color image obtained by the combination of the image taken with the IR cut filter (B), longpass filtered image $(\mathrm{G})$, and the InGaAs image (R).

Some pentimenti or not-visible aspects of the pictorial composition are colored in dark blue, too. Small pentimenti are related to the position of arms, legs, foot, and hands of all the figures represented. The false-color image highlights some details near the grape leaves and shadows of the rock on which Noah is lying down which are difficult to interpret. Drapes and clothes present some light changings, except for Ham's dress that shows another profile on the left side.

Three important pentimenti were found in the figures representing the three sons of Noah: (1) The face of the son placed on the left side was shifted, in fact we, can recognize another profile in the false-color image; (2) the son placed in the background right side shows short hair in the reflectograms. This is an important aspect that matches with the red chalk drawing placed at the Metropolitan Museum attribute to Andrea Sacchi, showed in Figure 4; (3) the son in the foreground shows two faces: The older version seems smaller than the last one. Furthermore, Ham's dress shows another profile on the left side.

False-color with only three images is a reductive approach, as it cannot produce an exhaustive analysis of post-processed images. A significant improvement in the ability to analyze multispectral data is obtained by stacking multibands VIS, NIR, and SWIR images in a spectral cube and performing additional processing through Hypertools (a free Matlab GUI).

In order to improve the readability of the pentimenti, we computed the principal component analysis (PCA) of the entire set of multiple images after mean centering and singular values decomposition (SVD). A false-color image (called also raw data) was obtained by combining the first three components of the entire set of VIS-NIR-SWIR in a RGB image (Figure 5a). The score images obtained from single components coded as color grade are also shown in Figure 5b-d. It resulted that the PC1 explains approximately $94.5 \%$ of the variability, while PC2 and PC 3 represent about $3.5 \%$ and $1.5 \%$. The images obtained by PCA are expected to better highlight small differences appearing in the images acquired in partially overlapped spectral windows, since the PCA components are obtained by simultaneously 
considers all the acquired data, leaving out spectral correlations and highlighting the contrasts between spectral bands.

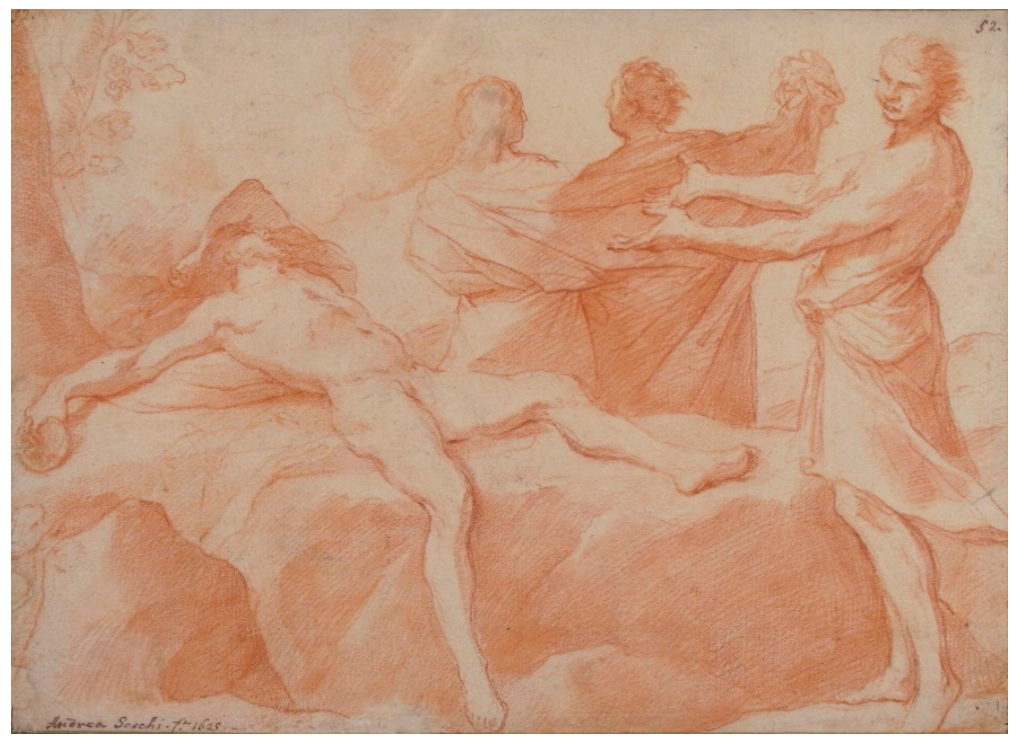

Figure 4. The Drunkenness of Noah drawing by Andrea Sacchi, Metropolitan Museum of New York (Accession Number: 1977.168).

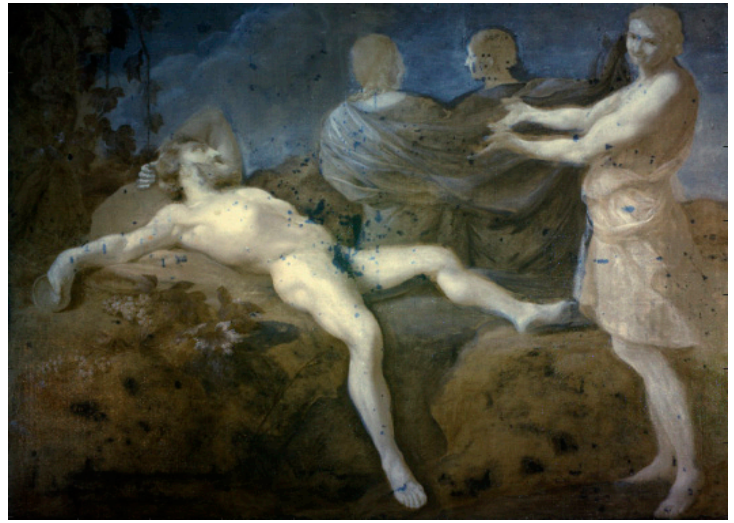

(a)

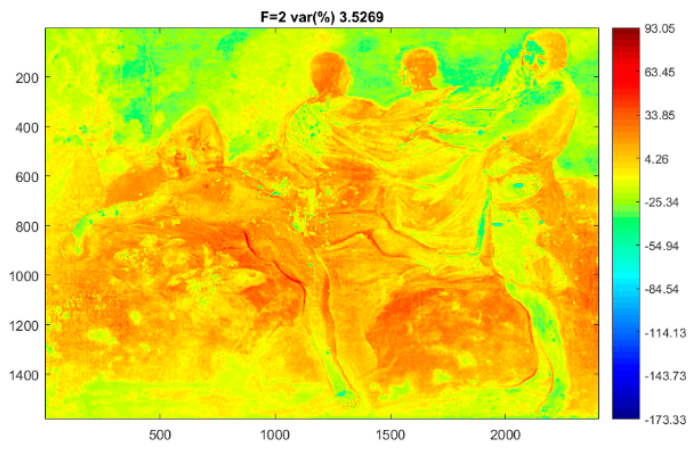

(c)

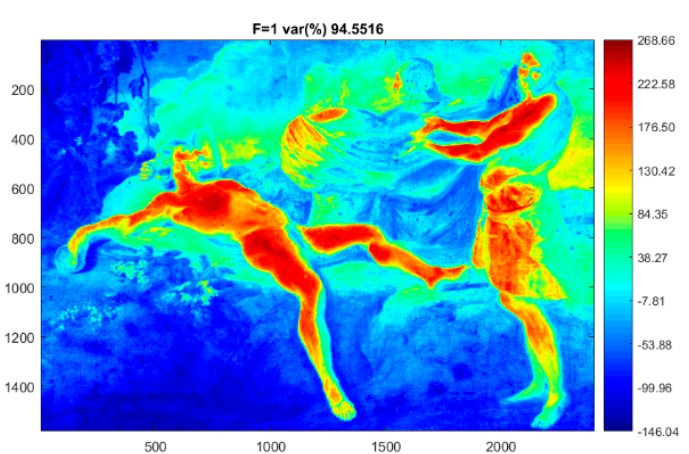

(b)

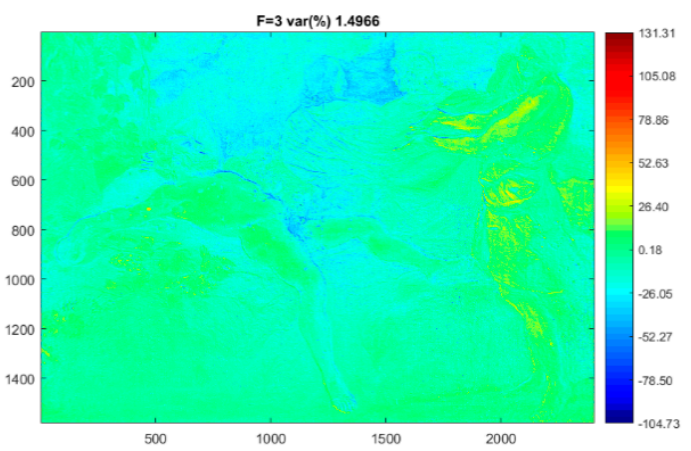

(d)

Figure 5. False-color image obtained from the first three components of the processed multispectral data cube (a), intensity color coded images form principal component analysis (PCA) components are shown respectively as PC1 (b), PC2 (c), and PC3 (d). 
The analysis reveals most of the pentimenti highlighted in the previous false-color image (see Figure 3). However, since the processing is not supervised, hidden details well highlighted in the IR images are occasionally not so well evidenced. For example, the two faces' sketches of the Noah's son in the foreground are better identified in the original InGaAs image, as shown in the detail in Figure 6 rather than in the PCA images. Nevertheless, it is worth mentioning that none of the spectral information contained in the original data set is lost by the PCA processing.

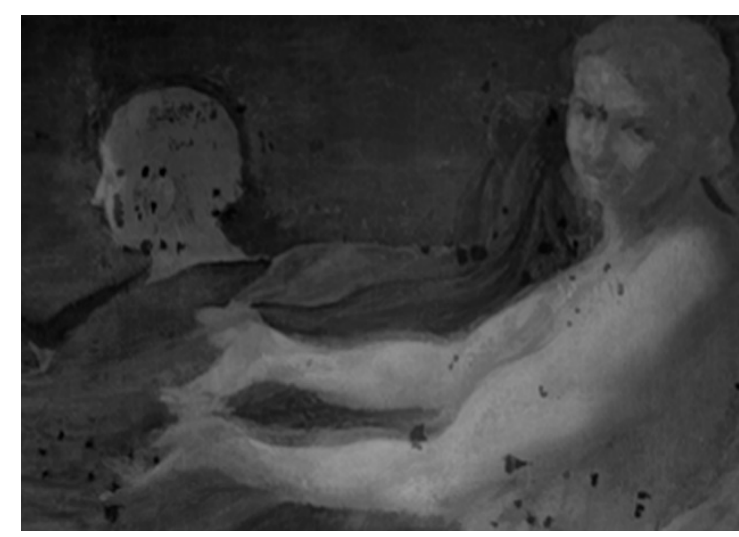

(a)

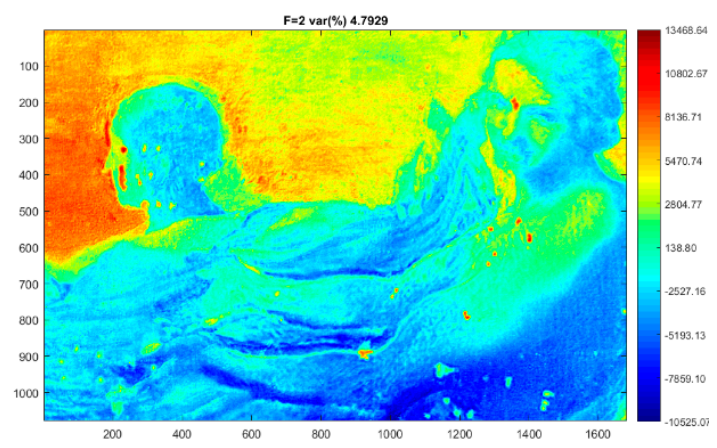

(c)

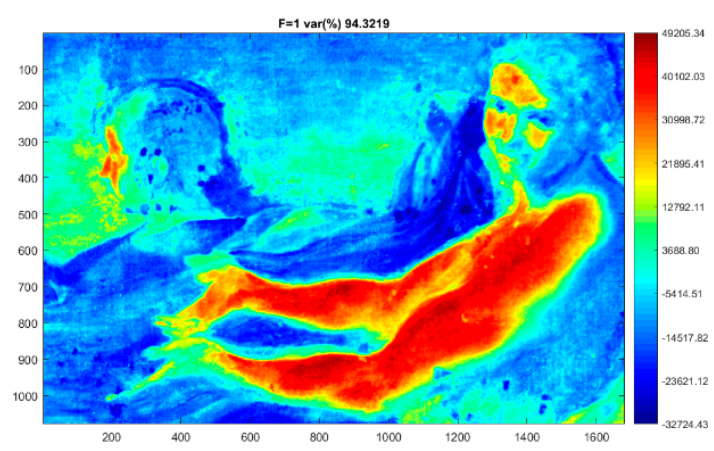

(b)

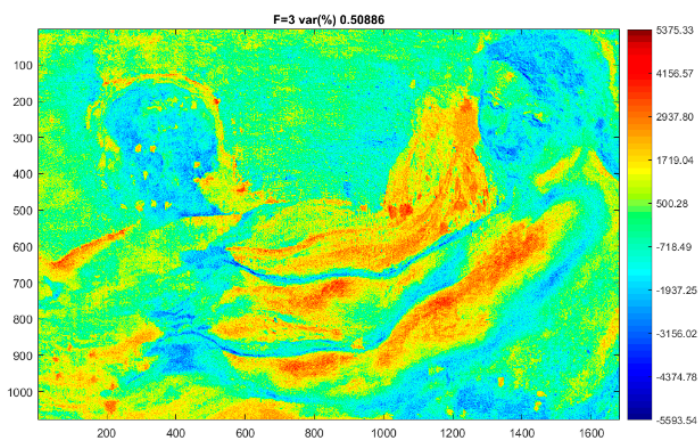

(d)

Figure 6. Detail of the painting. InGaAs image (a), PC1 (b), PC2 (c), and PC3 (d).

On the other hand, PC2 evidences few details not clearly identified in the InGaAs image: Here, the chin of the earlier version of Ham's face seems to have undergone changes, as shown in Figure 7.

To complete the investigation of the pentimenti, we performed radiographic images in the three most interesting parts of the paintings: Noah's sons heads (Figure 8). The radiographic images showed the same pentimenti already seen in the post-processed VIS-NIR-SWIR images. Moreover, the radiography performed on the double face of Noah's son was evidence of the presence of the chin, reinforcing and confirming the findings of the PC2 image. 


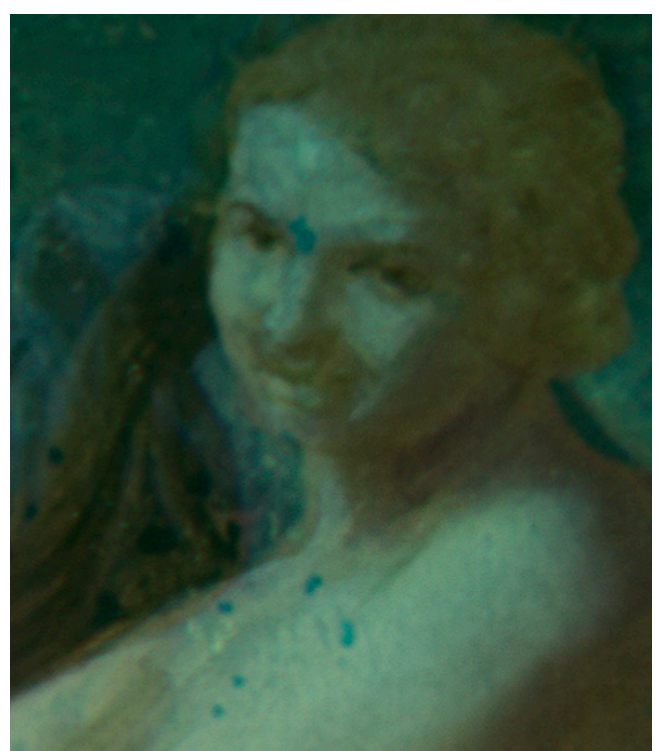

(a)

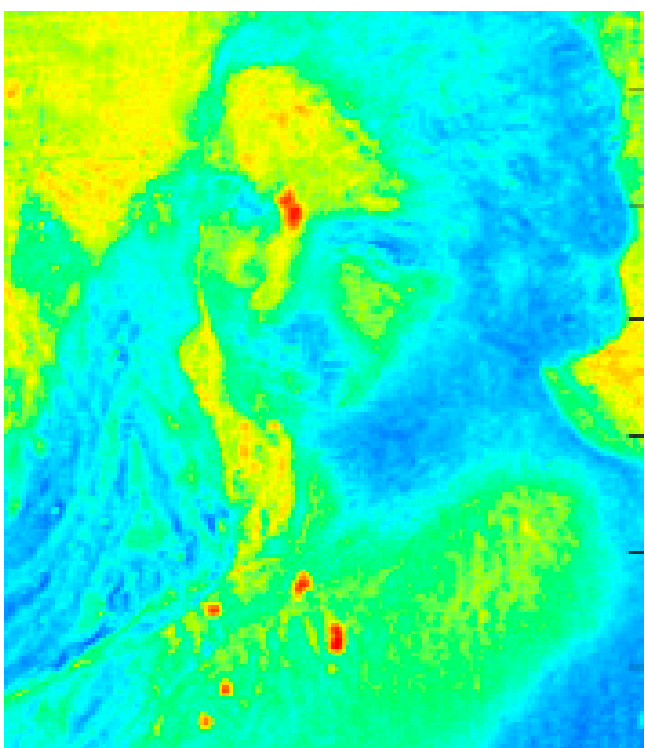

(b)

Figure 7. Detail of the painting. False-color image obtained by not post-processed images (a) and PC2 restituted as intensity coded colors (b).

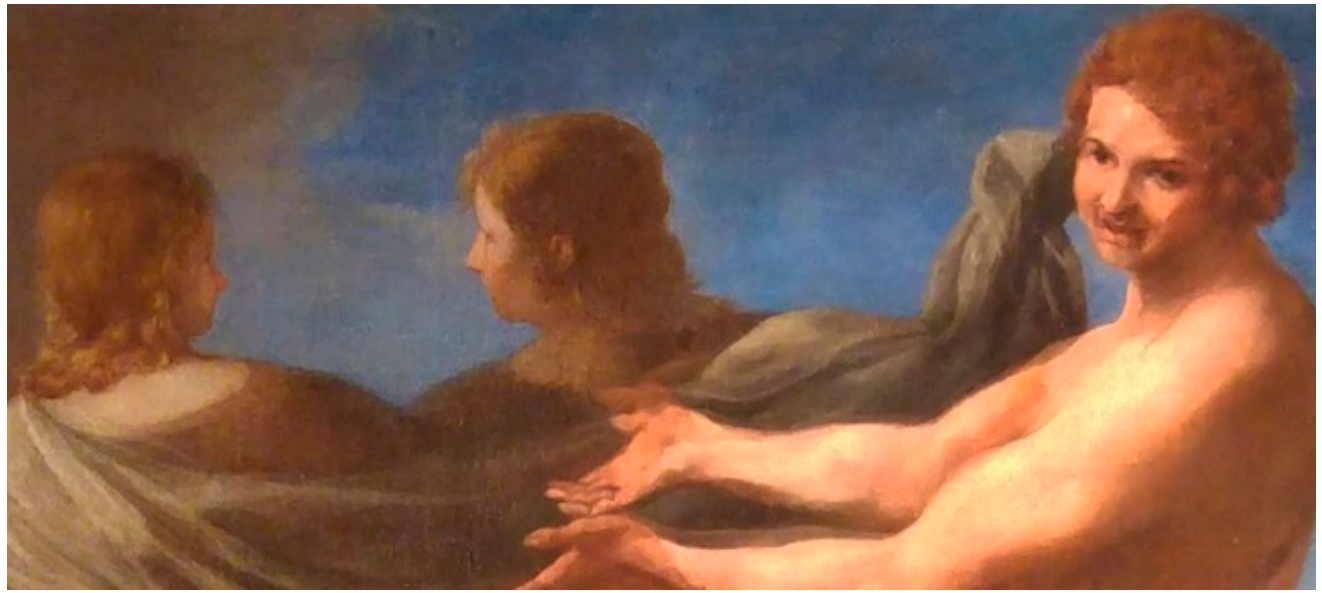

(a)

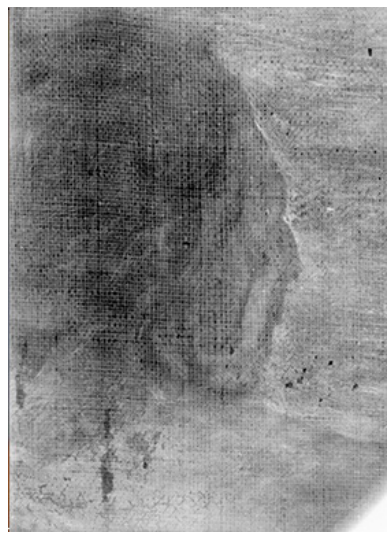

(b)

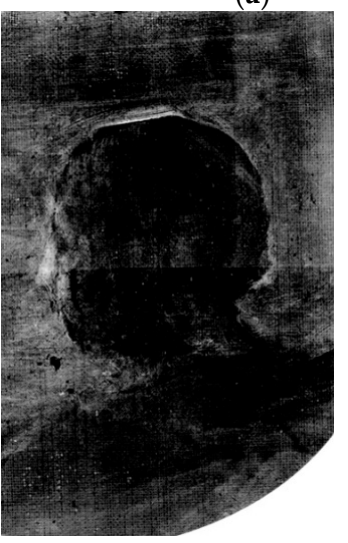

(c)

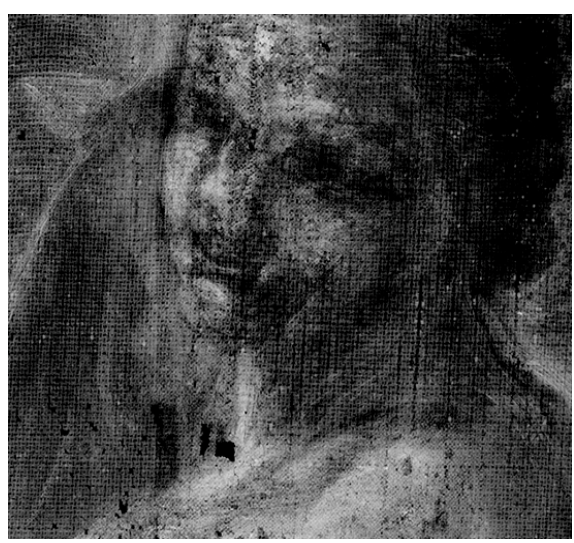

(d)

Figure 8. Detail of the painting (a). Radiographic images of Noah's sons (b-d). 


\section{Conclusions}

Infrared reflectography performed by selecting different spectral regions permits to highlight several hidden details of the painting. We presented an almost complete diagnostic analysis for the study of Drunkenness of Noah's underdrawings and pentimenti, exploiting the limitation of the univariate approach versus a more exhaustive multivariate approach. Multivariate approach was investigated by applying a "soft" post-processing procedure, modifying the consolidated false-color RGB combination by inserting the gray scaled visible image in one channel and two infrared images at different spectral ranges in the other ones. This method emphasized the differences between visible and underdrawing features, permitting an easier visualization of the meaningful areas. The use of PCA was very important to reveal other spectral variances that were confirmed by radiographic images.

We confirmed that the multispectral image acquisition is required and recommended to visualize hidden details of a painting. In addition, post-processing reveals important spectral features which were not visible otherwise, starting from non-conventional false-color images to chemometric methods (such as PCA).

The occurrence of the pentimenti found here shows that the composition originally conceived differs from its final realization. Except for the pentimenti, which regard the small changes in the position of the represented figures, the short hair of the Noah's son in the background, realized in the first instance, remains the main aspect to investigate further. As a matter of fact, these features are similar to the drawing conserved at the Metropolitan Museum. Although it is not possible to make definitive conclusions without carefully studying the paintings exhibited in the other museums, the occurrence of the pentimenti suggests that this painting could be one of the first versions realized by the original artist.

The next step will be the analysis of the other Drunkenness of Noah versions painted by Andrea Sacchi in order to add diagnostic information to be further integrated with documental, stylistic, and artistic expertise.

Author Contributions: Investigation, L.P., M.R., G.V.R., O.T., M.C., and A.P.; writing-original draft, L.P.; writing—review and editing, M.C.G., M.M., and F.C.

Funding: This research was funded by ADAMO project (2.10.2018-1.01.2020). The ADAMO Project is funded within the Center-of-Excellence (CoE) of the District of Technologies for Culture (DTC) by Regione Lazio.

Acknowledgments: The authors wish to acknowledge the Conservator of Palazzo Chigi (Ariccia, Rome): Arch. Francesco Petrucci for his kind availability. Thanks to Fernanda Benetti (INFN-LNF) for her collaboration for in situ measurements.

Conflicts of Interest: The authors declare no conflict of interest. The funders had no role in the design of the study; in the collection, analyses, or interpretation of data; in the writing of the manuscript, or in the decision to publish the results.

\section{References}

1. Gavrilov, D.; Maeva, E.; Grube, O.; Vodyanoy, I.; Maev, R. Experimental Comparative Study of the Applicability of Infrared Techniques for Non-destructive Evaluation of Paintings. J. Am. Inst. Conserv. 2013, 52, 48-60. [CrossRef]

2. Attas, M.; Cloutis, E.; Collins, C.; Goltz, D.; Majzels, C.; Mansfield, J.R.; Mantsch, H.H. Near-infrared spectroscopic imaging in art conservation: Investigation of drawing constituents. J. Cult. Herit. 2003, 4, 127-136. [CrossRef]

3. Dooley, K.A.; Facini, M. Revealing Degas's process and material choices in a late pastel on tracing paper with visible-to-near-infrared reflectance imaging spectroscopy. J. Am. Inst. Conserv. 2019, 58, 108-121. [CrossRef]

4. Cardeira, A.M.; Longelin, S.; Costa, S.; Candeias, A.; Carvalho, M.L.; Manso, M. Multi-analytical characterisation of D'Aprés Cormon by José Veloso Salgado. Nucl. Instrum. Methods Phys. Res. Sect. B Beam Interact. Mater. Atoms 2014, 331, 271-274. [CrossRef] 
5. Fontana, R.; Barucci, M.; Dal Fovo, A.; Pampaloni, E.; Raffaelli, M.; Striova, J. Multispectral IR Reflectography for Painting Analysis. In Advanced Characterization Techniques, Diagnostic Tools and Evaluation Methods in Heritage Science; Springer International Publishing: Basel, Switzerland, 2018; pp. 33-47.

6. Bonifazzi, C.; Carcagnì, P.; Fontana, R.; Greco, M.; Mastroianni, M.; Materazzi, M.; Pampaloni, E.; Pezzati, L.; Bencini, D. A scanning device for VIS-NIR multispectral imaging of paintings. J. Opt. A Pure Appl. Opt. 2008, 10, 064011. [CrossRef]

7. Green, R.O.; Eastwood, M.L.; Sarture, C.M.; Chrien, T.G.; Aronsson, M.; Chippendale, B.J.; Faust, J.A.; Pavri, B.E.; Chovit, C.J.; Solis, M.; et al. Imaging Spectroscopy and the Airborne Visible/Infrared Imaging Spectrometer (AVIRIS). Remote Sens. Environ. 1998, 65, 227-248. [CrossRef]

8. Polder, G.; Van der Heijden, G.W.A.M.; Young, I.T. Spectral image analysis for measuring ripeness of tomatoes. Trans. ASAE 2002, 45, 1152. [CrossRef]

9. Kim, M.S.; Chen, Y.R.; Mehl, P.M. Hyperspectral reflectance and fluorescence imaging system for food quality and safety. Trans. ASAE 2001, 44, 721-729.

10. Martin, M.E.; Wabuyele, M.; Panjehpour, M.; Overholt, B.; DeNovo, R.; Kennel, S.; Cunningham, G.; Vo-Dinh, T. An AOTF-based dual-modality hyperspectral imaging system (DMHSI) capable of simultaneous fluorescence and reflectance imaging. Med. Eng. Phys. 2006, 28, 149-155. [CrossRef]

11. Fischer, C.; Kakoulli, I. Multispectral and hyperspectral imaging technologies in conservation: current research and potential applications. Stud. Conserv. 2006, 51, 3-16. [CrossRef]

12. Capobianco, G.; Bracciale, M.P.; Sali, D.; Sbardella, F.; Belloni, P.; Bonifazi, G.; Serranti, S.; Santarelli, M.L.; Cestelli Guidi, M. Chemometrics approach to FT-IR hyperspectral imaging analysis of degradation products in artwork cross-section. Microchem. J. 2017, 132, 69-76. [CrossRef]

13. Pronti, L.; Ferrara, P.; Uccheddu, F.; Pelagotti, A.; Piva, A. Identification of pictorial materials by means of optimized multispectral reflectance image processing. In Proceedings of the 2015 IEEE International Workshop on Information Forensics and Security, Rome, Italy, 16-19 November 2015.

14. Legnaioli, S.; Lorenzetti, G.; Cavalcanti, G.H.; Grifoni, E.; Marras, L.; Tonazzini, A.; Salerno, E.; Pallecchi, P.; Giach, G.; Palleschi, V. Recovery of archaeological wall paintings. Herit. Sci. 2013, 1, 1-9. [CrossRef]

15. Fragasso, L.; Masini, N. Postprocessing of Infrared Reflectography to Support the Study of a Painting: The Case of Vivarini's Polyptych. Int. J. Geophys. 2011, 2011, 1-8. [CrossRef]

16. Striova, J.; Ruberto, C.; Barucci, M.; Kunzelman, D.; Dal Fovo, A.; Pampaloni, E.; Fontana, R. Spectral Imaging Hot Paper Spectral Imaging and Archival Data in Analysing Madonna of the Rabbit Paintings by Manet and Titian. Wiley Online Libr. 2018, 57, 7408-7412.

17. Cosentino, A. Infrared Technical Photography for art examination. Preserv. Sci. 2016, 13, 1-6.

18. Grifoni, E.; Tonazzini, A.; Campanella, B.; Legnaioli, S.; Lorenzetti, G.; Marras, L.; Pagnotta, S.; Palleschi, V.; Poggialini, F.; Salerno, E. A New Infrared True-Color Approach for Visible-Infrared Multispectral Image Analysis. J. Comput. Cult. Herit. 2019, 2, 1-11. [CrossRef]

19. Pelagotti, A.; Pezzati, L.; Piva, A.; Mastio, A. Del Multispectral UV Fluorescence Analysis of Painted Surfaces. In Proceedings of the 14th European Signal Processing Conference (EUSIPCO 2006), Florence, Italy, 4-8 September 2006; p. 5.

20. Scientific Imaging for Cultural Heritage/Images Scientifiques Pour le Patrimoine. Available online: https: //copa.hypotheses.org/552 (accessed on 26 June 2019).

21. Pronti, L.; Felici, A.C.; Ménager, M.; Vieillescazes, C.; Piacentini, M. Spectral Behavior of White Pigment Mixtures Using Reflectance, Ultraviolet-Fluorescence Spectroscopy, and Multispectral Imaging. Appl. Spectrosc. 2017, 71, 2616-2625. [CrossRef]

22. Prats-Montalbán, J.M.; de Juan, A.; Ferrer, A. Multivariate image analysis: A review with applications. Chemom. Intell. Lab. Syst. 2011, 107, 1-23. [CrossRef]

23. Tonazzini, A.; Salerno, E.; Abdel-Salam, Z.A.; Harith, M.A.; Marras, L.; Botto, A.; Campanella, B.; Legnaioli, S.; Pagnotta, S.; Poggialini, F.; et al. Analytical and mathematical methods for revealing hidden details in ancient manuscripts and paintings: A review. J. Adv. Res. 2019, 17, 31-42. [CrossRef]

24. Watanabe, M.; Watanabe, M.; Zhang, D.; Kanhangad, V.; Zhang, D.; Liu, L.L.; Teoh, A.B.J.; Shan, S.; Chen, X.; Gao, W.; et al. Principal Component Analysis. In Encyclopedia of Biometrics; Springer US: Boston, MA, USA, 2009; p. 1091. 
25. Hayem-Ghez, A.; Ravaud, E.; Boust, C.; Bastian, G.; Menu, M.; Brodie-Linder, N. Characterizing pigments with hyperspectral imaging variable false-color composites. Appl. Phys. A Mater. Sci. Process. 2015, 121, 939-947. [CrossRef]

26. Capobianco, G.; Bonifazi, G.; Prestileo, F.; Serranti, S. Pigment identification in pictorial layers by Hyper-Spectral Imaging. In Proceedings of the Advanced Environmental, Chemical, and Biological Sensing Technologies XI, Baltimore, MD, USA, 5-6 May 2014; SPIE: Bellingham, WA, USA, 2014.

27. Comelli, D.; Nevin, A.; Valentini, G.; Osticioli, I.; Castellucci, E.M.; Toniolo, L.; Gulotta, D.; Cubeddu, R. Insights into Masolino's wall paintings in Castiglione Olona: Advanced reflectance and fluorescence imaging analysis. J. Cult. Herit. 2011, 12, 11-18. [CrossRef]

28. Mercuri, F.; Buonora, P.; Cicero, C.; Helas, P.; Manzari, F.; Marinelli, M.; Paoloni, S.; Pasqualucci, A.; Pinzari, F.; Romani, M.; et al. Metastructure of illuminations by infrared thermography. J. Cult. Herit. 2018, 31, 53-62. [CrossRef]

29. Colantonio, C.; Pelosi, C.; D’Alessandro, L.; Sottile, S.; Calabrò, G.; Melis, M. Hypercolorimetric multispectral imaging system for cultural heritage diagnostics: an innovative study for copper painting examination. Eur. Phys. J. Plus 2018, 133, 526. [CrossRef]

30. Khaleghi, B.; Khamis, A.; Karray, F.O.; Razavi, S.N. Multisensor data fusion: A review of the state-of-the-art. Inf. Fusion 2013, 14, 31-44. [CrossRef]

31. Koch Dandolo, C.L.; Lopez, M.; Fukunaga, K.; Ueno, Y.; Pillay, R.; Giovannacci, D.; Le Du, Y.; Bai, X.; Menu, M.; Detalle, V. Toward a multimodal fusion of layered cultural object images: complementarity of optical coherence tomography and terahertz time-domain imaging in the heritage field. Appl. Opt. 2019, 58, 1281-1290. [CrossRef]

32. Amanatiadis, S.; Apostolidis, G.; Karagiannis, G. Fusion of the infrared imaging and the ultrasound techniques to enhance the sub-surface characterization. In Proceedings of the Communications in Computer and Information Science, Ávila, Spain, 26-28 June 2019; Springer: Berlin/Heidelberg, Germany, 2019.

33. Alfeld, M.; Pedetti, S.; Martinez, P.; Walter, P. Joint data treatment for Vis-NIR reflectance imaging spectroscopy and XRF imaging acquired in the Theban Necropolis in Egypt by data fusion and t-SNE. C. R. Phys. 2018, 19, 625-635. [CrossRef]

34. Arcangeli, L. Andrea Sacchi. Ebrezza di Noé; Museo del Barocco-Palazzo Chigi in Ariccia: Ariccia, Italy, 2010. 